\title{
BMJ Open US-based cross-sectional survey of clinicians' knowledge and attitudes about shared decision-making across healthcare professions and specialties
}

\author{
Rachel C Forcino, ${ }^{1}$ Renata West Yen, ${ }^{1}$ Maya Aboumrad, ${ }^{1,2}$ Paul J Barr, ${ }^{1}$ \\ Danielle Schubbe, ${ }^{1}$ Glyn Elwyn, ${ }^{1}$ Marie-Anne Durand ${ }^{1}$
}

To cite: Forcino RC, Yen RW, Aboumrad M, et al. USbased cross-sectional survey of clinicians' knowledge and attitudes about shared decision-making across healthcare professions and specialties. BMJ Open 2018;8:e022730. doi:10.1136/ bmjopen-2018-022730

- Prepublication history and additional material for this paper are available online. To view these files, please visit the journal online (http://dx.doi org/10.1136/bmjopen-2018022730).

Received 8 March 2018 Revised 12 June 2018 Accepted 12 September 2018

A) Check for updates

(C) Author(s) (or their employer(s)) 2018. Re-use permitted under CC BY-NC. No commercial re-use. See rights and permissions. Published by BMJ.

${ }^{1}$ The Dartmouth Institute for Health Policy \& Clinical Practice, Dartmouth College, Lebanon, New Hampshire, USA

${ }^{2}$ White River Junction VA Medical Center, White River Junction, Vermont, USA

Correspondence to Dr Marie-Anne Durand; marie-anne.durand@dartmouth. edu

\section{ABSTRACT}

Objective In this study, we aim to compare shared decision-making (SDM) knowledge and attitudes between US-based physician assistants (PAs), nurse practitioners (NPs) and physicians across surgical and family medicine specialties.

Setting We administered a cross-sectional, web-based survey between 20 September 2017 and 1 November 2017.

Participants 272 US-based NPs, PA and physicians completed the survey. 250 physicians were sent a generic email invitation to participate, of whom 100 completed the survey. 3300 NPs and PAs were invited, among whom 172 completed the survey. Individuals who met the following exclusion criteria were excluded from participation: (1) lack of English proficiency; (2) area of practice other than family medicine or surgery; (3) licensure other than physician, PA or NP; (4) practicing in a country other than the US.

Results We found few substantial differences in SDM knowledge and attitudes across clinician types, revealing positive attitudes across the sample paired with low to moderate knowledge. Family medicine professionals (PAs) were most knowledgeable on several items. Very few respondents (3\%; 95\% Cl 1.5\% to $6.2 \%)$ favoured a paternalistic approach to decision-making.

Conclusions Recent policy-level promotion of SDM may have influenced positive clinician attitudes towards SDM. Positive attitudes despite limited knowledge warrant SDM training across occupations and specialties, while encouraging all clinicians to promote SDM. Given positive attitudes and similar knowledge across clinician types, we recommend that SDM is not confined to the patientphysician dyad but instead advocated among other health professionals.

\section{INTRODUCTION}

Team-based care is defined as "the provision of health services to individuals, families and/ or their communities by at least two health providers' . ${ }^{1}$ This model is increasingly prominent across the healthcare delivery spectrum, with advanced practice clinicians such as nurse practitioners (NPs) and physician assistants (PAs), who have their own patient

\section{Strengths and limitations of this study}

- This study represents the first US national survey comparing shared decision-making knowledge and attitudes across diverse clinician groups.

- The survey instrument was rigorously developed based on a literature search of high-quality evidence, primarily including systematic reviews.

- The sample was derived from an online panel of respondents and may not be representative of the full US populations of these professionals.

- We were unable to fully field the surgical physician assistant quota in this exploratory study.

panels, order and perform tests and procedures and prescribe medications, working alongside physicians from cardiology wards to primary care clinics. ${ }^{23}$ Yet, little is known about the congruence of team members' perceptions regarding approaches to healthcare practice and communication such as shared decision-making (SDM).

Prior research has explored similarities and differences in care delivered by physicians and advanced practice clinicians. ${ }^{4-6}$ However, little attention has been given to differences between professions specific to patient-centred attitudes or behaviour. Swan and colleagues found NPs and physicians to receive comparable patient satisfaction ratings in primary care settings, ${ }^{4}$ while Hojat and colleagues found hospital-based NPs to attain significantly higher empathy scores than hospital-based physicians on the previously validated Jefferson Scale of Physician Empathy. ${ }^{5}$ Further, Laurant and colleagues found NPs and PAs to achieve similar clinical outcomes to those of physicians when working in physician-like roles. ${ }^{6}$ Advanced practice clinicians bring diverse clinical backgrounds and valuable perspectives to patient-centred care while maintaining patient satisfaction 
and clinical outcomes similar to those of their physician colleagues.

SDM, a process by which clinicians and patients make decisions together using the best available evidence about the likely benefits and harms of each option, and where patients are supported to arrive at informed preferences, is considered to be a key component of patient-centred care. ${ }^{7-9}$ However, while the number of advanced practice clinicians participating in routine patient care in the USA doubled in the 1990s,${ }^{10}$ prior SDM research has largely focused on the patient-physician dyad without accounting for roles of other team members. ${ }^{11}$ A review by Clark and colleagues takes stock of the SDM literature and suggests that registered nurses are well-suited to engage in SDM, but does not contribute additional empirical evidence on the topic. ${ }^{12}$ Légaré and colleagues developed and validated an interprofessional model for SDM, ${ }^{11}{ }^{13}$ but did not assess its impact on SDM among a range of clinician types. Further, previous literature has identified high patient-orientation among primary care physicians and lower patient-orientation among surgeons. ${ }^{14}$ For this reason, we focus on comparing family medicine and surgical care specialties across several healthcare professions.

A gap exists in the literature examining attitudes and knowledge about SDM among a diverse group of surgical and primary care clinicians, including physicians, NPs and PAs. Early streams of research in the area of SDM and team-based care, paired with growth and increased focus on the role of advanced practice clinicians in the US, raises important questions about SDM knowledge and attitudes across the varied roles of healthcare team members. In this study, we aim to compare SDM knowledge and attitudes between US-based PAs, NPs and physicians across surgical and family medicine specialties.

\section{METHOD}

This study was designed and reported according to the Checklist for Reporting Results of Internet E-Surveys. ${ }^{15}$ We administered a voluntary, cross-sectional, web-based survey to members of an internet panel of healthcare providers organised by SERMO, a healthcare market research company.

\section{Survey design}

Survey development drew on a review of existing literature and was derived from another cross-sectional, web-based survey administered to medical students in four countries. ${ }^{16}$ The first iteration of the online survey was developed in 2013 and piloted in a small-scale online study conducted in the UK, recruiting medical students through online forums. ${ }^{16}$ It was subsequently refined and reworded for Durand's study of medical students' attitudes and knowledge about SDM, then revised for the current study. ${ }^{16}$

The current web-based survey included 28 items presented over 14 screens, each of which included a 'back' button that allowed for review of prior survey screens. The first question was open-ended, asking participants to define SDM. The following screen provided a definition of SDM adapted from Elwyn $e t a l^{7}$ Ten attitudinal items with a 4-option Likert-type response scale (1=strongly disagree; $4=$ strongly agree) were informed by established barriers and facilitators to $\mathrm{SDM}^{17-22}$ and included one item from the Jefferson Scale of Physician Empathy. ${ }^{5}$ Ten subsequent true-false knowledge items were based on prior literature detailing SDM process and outcomes. ${ }^{23-27}$ A final multiple-choice item presented a generic clinical scenario and asked which response option best matched how the respondent would make his or her treatment decision, with response options based on Emanuel's four models of the physician-patient relationship. ${ }^{28}$ The clinical scenario was initially drafted by experts in SDM with input from clinicians for Durand's study of medical students' attitudes and knowledge about SDM. ${ }^{16}$ It was revised for the current study to be made more generic and applicable to multiple fields and practices. The survey closed with two demographic items asking participant gender and number of years in practice. See supplementary appendix A1 for the questionnaire.

No more than 10 items were included on any single screen. Participants were required to respond to each item in order to continue through the survey. To attenuate bias from order effects, item order was randomised for (1) the 10 attitudinal items and (2) the 10 knowledge items. Response option order was randomised for the multiple-choice item. The web-based survey was pretested for accuracy, usability and technical functionality by three members of the research team prior to fielding.

\section{Patient involvement}

As the survey focused on knowledge and atittudes among clinicians, patients were not directly involved in the design or administration of this research study.

\section{Participants}

Participants were US-based PAs, NPs and physicians including doctors of medicine (MD) and doctors of osteopathic medicine (DO), all of whom work in family medicine or surgery. Screening questions were included at the beginning of the survey to exclude respondents meeting the following exclusion criteria: (1) lack of English proficiency; (2) area of practice other than family medicine or surgery; (3) licensure other than physician, PA or NP; (4) practicing in a country other than the US.

This focus on clinicians specialising in family medicine and surgery was intended to pursue maximum variation in SDM knowledge and attitudes among our sample of healthcare professionals, as there is evidence of high patient-orientation among primary care physicians and lower patient-orientation among surgeons. ${ }^{14}$ Inclusion of physicians, NPs and PAs was intended to further explore differences in patient-centeredness and empathy between professions demonstrated in prior research. ${ }^{52}$ 
Given the novelty of the survey instrument, we lacked an effect size estimate on which to base sample size calculations. We therefore followed an established rule of thumb recommending a minimum sample size of 50 per comparison group..$^{30}$ Our goal was therefore to recruit 50 participants per clinician type (ie, family medicine physician, surgery physician, family medicine PA, surgery PA, family medicine NP, surgery NP) to total 300 participants and allow the recommended but flexible minimum of 5-10 observations per parameter in logistic regression analysis. ${ }^{31} 32$

\section{Procedure}

To advertise the survey, SERMO distributed email invitations to members of its survey panel; see online supplementary appendix A2 for the email invitation. Within the email invitation, participants were offered cash honoraria which, per SERMO policy, varied in amount up to $\$ 30$ on completion of the survey to incentivise participation. The survey weblink within the email invitation led to an information sheet that included an estimated time commitment for survey completion $(5 \mathrm{~min})$. The information sheet also provided information about the purpose of the study, the name of the principal investigator, data security (ie, the research team will not have access to participants' personal information) and confirmation that further participation in the survey represented consent to participate in the research study. SERMO tracked and ensured unique responses through a postsubmission log file check via internal server-side script. Completeness checks were done via Javascript prior to questionnaire submission. Only complete questionnaires were included in the analysis.

\section{Data analysis}

Due to our maximum-variation sampling approach, we did not weight or otherwise adjust the data. For closedended item responses, we calculated frequencies and descriptive statistics to allow comparison across clinician groups. We calculated SDM knowledge scores (0-10) representing the number of correct true-false knowledge responses for each participant. We compared mean knowledge scores across responses to the multiple choice item representing Emanuel's four models of the physician-patient relationship ${ }^{28}$ as well as by response to the SDM definition item. Through multiple logistic regression analysis followed by postestimation z-tests, we assessed differences in individual SDM knowledge item responses by profession and area of practice while controlling for previous formal SDM training, clinician gender, preferred decision-making approach and number of years in practice. We calculated the average predicted probability of answering each knowledge item correctly while adjusting for all other variables in the model. We similarly used multiple regression analysis and postestimation z-tests to assess differences in SDM attitudes by profession and area of practice while controlling for knowledge score, adequacy of
SDM definition, previous formal SDM training, clinician gender, preferred decision-making approach and number of years in practice. We again calculated the average predicted probability of expressing a favourable attitude about SDM for each item while adjusting for all other variables in the model. Statistical significance was defined by an alpha level $\leq 0.05$.

For the single open-ended item (defining SDM), one member of the research team coded responses as adequate if they explicitly mentioned both patient and clinician involvement in decision-making; all other responses were coded as inadequate and/or incomplete. All responses were further coded to indicate whether SDM definitions mentioned incorporating evidence in deciding what to do next with the patient. This coding system was based on Elwyn's definition of SDM as an 'approach where physicians and patients make decisions together, using the best available evidence about the likely benefits and harms of each option, and where patients are supported to arrive at informed preferences'. ${ }^{7}$ Another member of the research team coded all open-ended responses based on common language and content. The first researcher analysed all dual-coded data to identify themes arising from respondents' SDM definitions.

\section{RESULTS}

\section{Participants}

A total of 250 physicians received generic email invitations to participate in the survey, of whom 100 completed the survey. A total of 3300 NPs and PAs were invited, among whom 172 completed the survey. In total, 272 individuals completed the survey between 20 September 2017 and 1 November 2017. Among those accessing the survey link, the rate of initial agreement to participate was $98.6 \%$, with 703 of the 713 who accessed the survey agreeing to participate. Of those who agreed to participate, $74 \%$ met all inclusion criteria and were eligible to proceed $(518 / 703)$. The completion rate was $38.7 \%$, with 272 of the 703 individuals who agreed to participate being eligible for participation and fully completing the survey. With regard to survey non-completers, 15 dropped out in the first several screening items establishing eligibility, 230 were excluded from participation because their respective quotas were full at the time they accessed the survey, 149 were excluded because they did not meet the inclusion criterion requiring a specialisation in family medicine or surgery and one person dropped out in the main body of the survey.

By clinician type, 50 surgical NPs, 54 family medicine NPs, 16 surgical PAs, 52 family medicine PAs, 50 surgeons and 50 family medicine physicians completed the survey. Participants averaged 13.41 years in practice, with $26.5 \%$ (72/272; 95\% CI 21.3 to 32.1) receiving previous formal SDM training. A full demographic profile of participants is provided in table 1 . 
Table 1 Participant characteristics

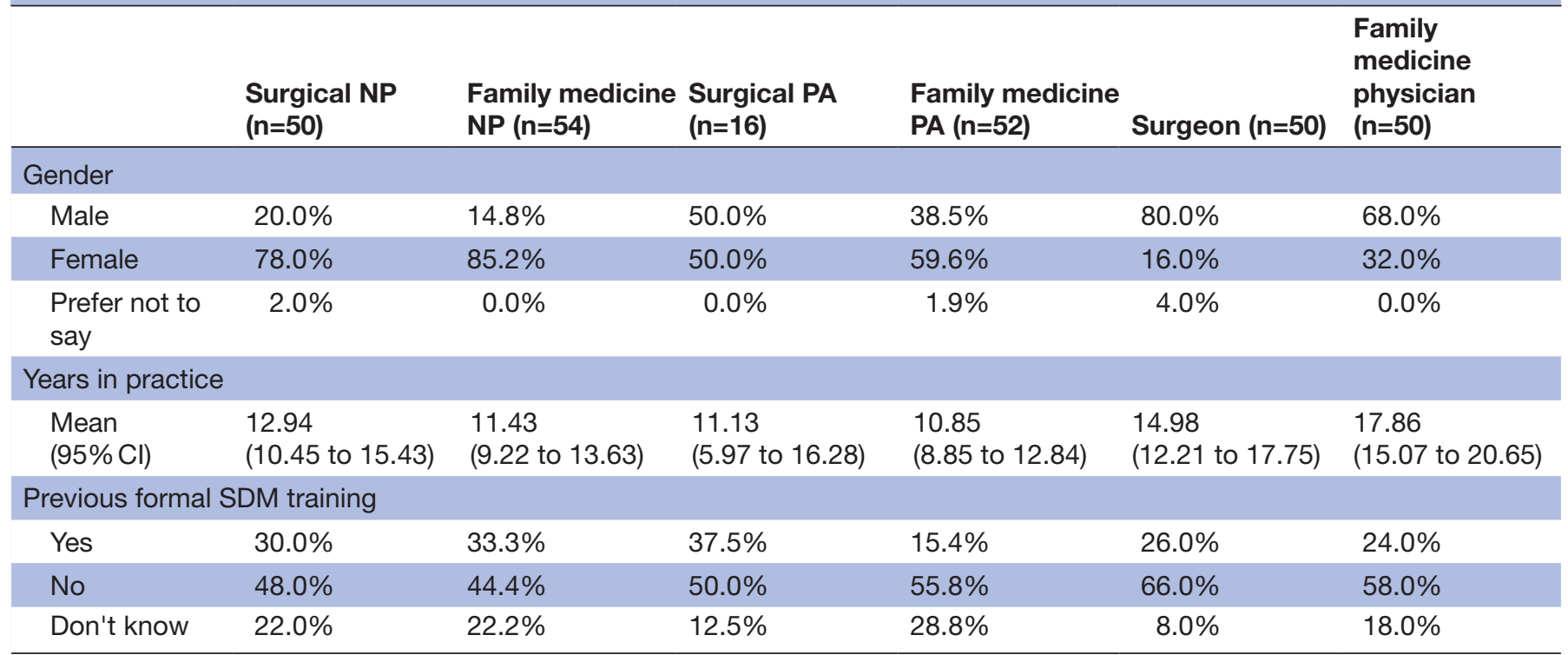

NPs, nurse practitioners; PAs, physician assistants; SDM, shared decision-making.

\section{SDM knowledge}

Knowledge by profession and clinical specialty

Mean knowledge scores, representing the average number of knowledge items answered correctly and ranging $0-10$, appeared to be similar across all professions and clinical specialties based on descriptive statistics. Mean knowledge scores were relatively consistent across responses to the multiple-choice item representing four models of the physician-patient relationship. The few respondents $(\mathrm{n}=9)$ favouring a paternalistic approach demonstrated the least SDM knowledge $(5.11 ; 95 \%$ CI 3.51 to 6.72 ) and respondents favouring deliberative $(5.92 ; 95 \% \mathrm{CI}$ 5.68 to 6.16$)$ and informative (5.92; $95 \%$ CI 5.69 to 6.14 ) approaches had the highest average knowledge scores. Descriptions of the four models of the physician-patient relationship are available under the 'Preferred approach to decision-making' subheading below. Mean knowledge scores were also consistent across those who had (6.04; $95 \%$ CI 5.79 to 6.29 ) and had not reported to have (5.82; 95\% CI 5.62 to 6.01 ) previously received SDM training. As shown in figure 1, surgical NPs averaged 5.6 (SD 1.2) correct responses out of 10 total items, family medicine NPs 5.9 (SD 1.2) correct responses, surgical PAs 5.8 (SD 0.9 ) correct responses, family medicine PAs 6.0 (SD 1.6) correct responses, surgeons 5.8 (SD 1.4) correct responses and family medicine physicians 6.2 (SD 1.3) correct responses. With regard to individual knowledge items, few participants from any profession or clinical specialty correctly identified that there is limited evidence of the impact of SDM on treatment adherence $(27.6 \%$; $95 \% \mathrm{CI}$

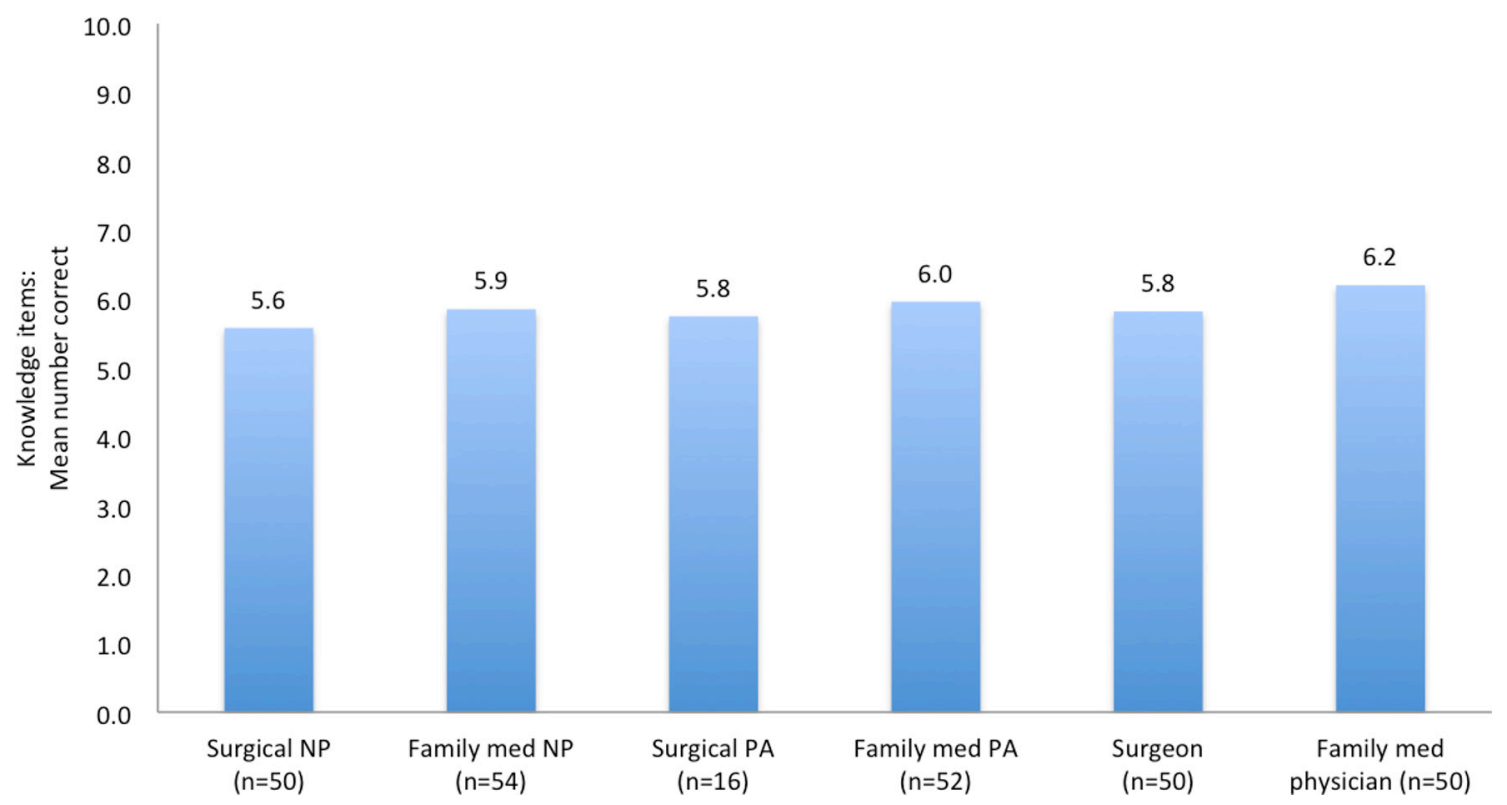

Figure 1 Knowledge scores by clinician type. NP, nurse practitioner; PA, physician assistant. 
Shared decision-making leads to improved affective-cognitive outcomes. (TRUE)

Shared decision-making interventions have a variable effect on the treatment option chosen. (TRUE)

Using shared decision-making interventions increases patient decision regret. (FALSE)

Shared decision-making interventions cause patients to fee uncertain about their decisions. (FALSE)

A majority of patients do not want to engage in shared decisionmaking with their clinicians. (FALSE)

Most people will understand natural frequency (e.g., 1 in every 100 people) better than a percentage. (TRUE)

Using shared decision-making interventions results in fewer patients choosing major surgery. (TRUE)

There is limited evidence of the impact of shared decision-making interventions on treatment adherence. (TRUE)

When communicating information about risks, it is best to use relative risk (e.g., there is double the risk of developing thrombosis when using oral contraceptives). (FALSE)

Shared decision-making interventions have not been shown to affect health outcomes. (TRUE)

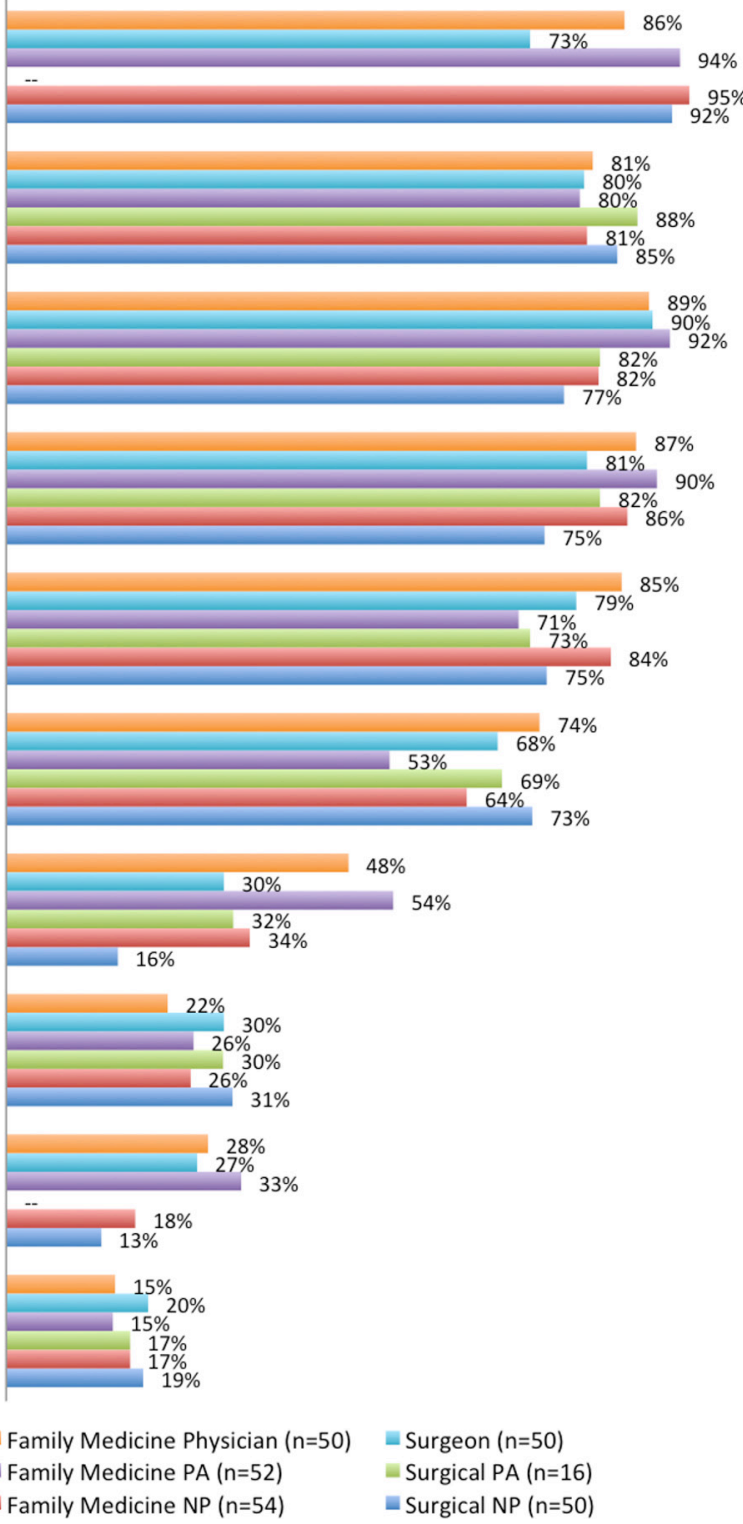

Figure 2 True/False knowledge items: Per cent correct by clinician type, adjusted by participant characteristics. NP, nurse practitioner; PA, physician assistant.

22.3 to 33.3 ) or that SDM interventions have not been shown to affect health outcomes $(17.6 \%$; $95 \%$ CI 13.3 to 22.7).

Differences between professions and clinical specialties were identified at the individual item level, including when adjusted for participants' demographic and personal characteristics (see figure 2). When asked whether using SDM interventions results in fewer patients choosing major surgery, family medicine NPs $(33.8 \%$; 95\% CI 20.3 to $47.2 ; \mathrm{p}=0.039)$, family medicine PAs $(53.7 \%$; $95 \% \mathrm{CI}$ 40.0 to $67.4 ; \mathrm{p}<0.000)$ and family medicine physicians ( $47.5 \%$; $95 \%$ CI 33.1 to $61.9 ; \mathrm{p}=0.002$ ) were all significantly more likely than the surgical NP $(15.5 \%$; $95 \%$ CI 5.0 to 26.0) reference group to provide the correct answer of 'true'; family medicine PAs (53.7\%; 95\% CI 40.0 to 67.4 ) were more likely than both family medicine NPs (33.8\%; 95\% CI 20.3 to 47.2; $\mathrm{p}=0.045)$ and surgeons ( $30.2 \%$; $95 \%$ CI 16.8 to $43.7 ; \mathrm{p}=0.026)$ to do so. While a majority of all participants incorrectly responded that it is best to use relative risk when communicating information about risks, family medicine PAs (32.6\%; 95\% CI 19.7 to $45.5 ; \mathrm{p}=0.024)$ were more likely than the surgical NP (13.2\%; 95\% CI 3.9 to 22.6) reference group to answer correctly. However, family medicine PAs $(53.2 \%$; $95 \%$ CI 39.6 to $66.8 ; \mathrm{p}=0.032)$ performed worse than the surgical NP (73.0\%; 95\% CI 60.4 to 85.6) reference group on the other risk communication knowledge item, as only half correctly identified that most people will understand natural frequency better than a percentage.

Family medicine PAs (90.3\%; 95\% CI 82.4 to 98.3; $\mathrm{p}=0.036)$ were also more likely than the surgical NP (74.7\%; $95 \%$ CI $62.3 \%$ to $87.3 \%$ ) reference group to provide the correct answer of 'false' in response to the item stating that SDM interventions cause patients to feel uncertain about their decisions. Further, surgeons $(72.7 \%$; $95 \%$ CI 57.2 to $88.2 ; \mathrm{p}=0.019)$ were less likely than 


\begin{tabular}{|c|c|c|}
\hline Theme & Subthemes & Illustrative quote(s) \\
\hline \multirow[t]{2}{*}{$\begin{array}{l}\text { Input or involvement from } \\
\text { multiple people }\end{array}$} & $\begin{array}{l}\text { Multidisciplinary collaboration between } \\
\text { healthcare professionals }\end{array}$ & $\begin{array}{l}\text { 'Decisions arrived at with input from multiple h[ealth]c[are] team } \\
\text { members'; 'Discussion within the healthcare team and deciding } \\
\text { what's best for the patient' }\end{array}$ \\
\hline & $\begin{array}{l}\text { Patient involvement, at times including } \\
\text { family }\end{array}$ & 'Team approach using all divisions including patient and family' \\
\hline $\begin{array}{l}\text { Clinician(s) making the } \\
\text { decision for the patient }\end{array}$ & & $\begin{array}{l}\text { 'Working together as a team to collaborate and make decisions for } \\
\text { the betterment of the patient'; 'Where there is a team of people that } \\
\text { share the decision making for the patient' }\end{array}$ \\
\hline $\begin{array}{l}\text { Patient making the decision } \\
\text { autonomously or with } \\
\text { clinician support }\end{array}$ & & $\begin{array}{l}\text { 'Presenting best evidence to the patient and allowing the patient to } \\
\text { make an informed decision based on their values with my support'; } \\
\text { 'doctor makes suggestions, p[atien]t decides' }\end{array}$ \\
\hline & Patient-to-clinician & $\begin{array}{l}\text { 'Answers to clinical dilemmas that involve both the client and the } \\
\text { physician sharing knowledge and possible outcomes' }\end{array}$ \\
\hline
\end{tabular}

SDM, shared decision-making.

their surgical NP (92.4\%; 95\% CI 85.2 to 99.6) colleagues to correctly identify that SDM leads to improved affective-cognitive outcomes. Full logistic regression results are available in online supplementary materials 1 .

\section{SDM definitions}

Fewer than half of all participants provided a definition of SDM that explicitly described patient and clinician jointly involved in the decision-making process $(41.5 \%, 95 \% \mathrm{CI}$ $35.6 \%$ to $47.7 \%)$. Of those responses $(113 / 272 ; 41.5 \%)$, only nine also included a reference to the evidence on which shared decisions should be based. We did not identify substantial differences in mean knowledge scores by SDM definition, as the few respondents who defined SDM as patient and clinician jointly involved and included a reference to evidence had a mean knowledge score of 5.44 (95\% CI 4.35 to 6.54 ), those who correctly identified the participants in SDM but did not mention evidence averaged 5.94 (95\% CI 5.69 to 6.18) and those who defined SDM incorrectly averaged 5.83 (95\% CI 5.62 to 6.04 ).

Thematic analysis of the open-ended SDM definition responses revealed further nuance, detailed in table 2. Four themes were identified: (1) Input or involvement from multiple people; (2) Clinician(s) making the decision for the patient; (3) Patient making the decision autonomously or with clinician support and (4) Information exchange between patient and clinician(s). The first theme related to the involvement of multiple clinical team members in the decision-making process without referring to the patient and instead specifically referring to multidisciplinary collaboration between healthcare professionals. In an illustrative quote, one participant described SDM as 'decisions arrived at with input from multiple $\mathrm{h}$ [ealth]c[(are] team members'. A related theme involving an individual or care team making a decision without explicit patient input was also identified, with particular emphasis on a paternalistic approach to decision-making where clinicians make decisions 'for the patient'. A theme of information exchange often involved the clinician providing information to the patient. Far less prevalent was a subtheme of patient-to-clinician information exchange, where reference was made to patients sharing knowledge, insights or preferences as part of the decision-making process.

\section{SDM attitudes}

Attitudes by profession and clinical specialty

Overall, $84.2 \%$ (95\% CI 79.3 to 88.3 ) of participants reported that SDM was compatible with clinical practice guidelines. Additionally, $82 \%$ (95\% CI 76.9 to 86.4) of all participants disagreed when asked if they do not feel confident in their ability to engage in SDM. Family medicine NPs (93.0\%; 95\% CI 85.3 to 100) reported more confidence in their ability to engage in SDM than did family medicine physicians $(73.6 \%$; $95 \%$ CI 60.8 to $86.5 ; \mathrm{p}=0.020)$ or surgeons $(75.0 \%$; $95 \%$ CI 61.9 to 88.2 ; $\mathrm{p}=0.038)$. Three-quarters $(75.7 \%$; $95 \%$ CI 70.2 to 80.7$)$ of all participants disagreed that SDM takes too much time; however, family medicine physicians $(61.2 \%$; $95 \%$ CI 46.9 to 75.5) were significantly more likely than family medicine NPs $(84.5 \%$; $95 \%$ CI 74.4 to $94.6 ; \mathrm{p}=0.016)$ to think SDM takes too much time. Relating to clinician empathy, nearly all participants said they imagine themselves in their patients' shoes when providing care $(96.7 \%$ agreed; $95 \%$ CI 93.8 to 98.5 ).

Half of our sample (50.0\%; 95\% CI 43.9 to 56.1$)$ agreed that patients asking clinicians what to do, a commonly cited barrier to SDM, makes SDM challenging. However, 
I try to imagine myself in my patients' shoes when providing care to them. (agree or strongly agree)

I am not confident in my ability to engage in shared decision-making. (disagree or strongly disagree)

Shared decision-making is not compatible with clinical practice guidelines. (disagree or strongly disagree)

Doing shared decision-making takes too much time. (disagree or strongly disagree)

Doing shared decision-making may cause patients to question my clinical expertise. (disagree or strongly disagree)

Using shared decision-making with patients could increase my legal risk. (disagree or strongly disagree)

It's okay for a shared decision to stray from what I feel is the most clinically appropriate course of action. (agree or strongly agree)

Giving patients informational resources is sufficient to foster shared decision-making. (disagree or strongly disagree)

Shared decision-making can only be done with patients who are sufficiently educated to discuss treatment or screening options. (disagree or strongly disagree)

Shared decision-making is challenging because patients ask me to decide for them. (disagree or strongly disagree)
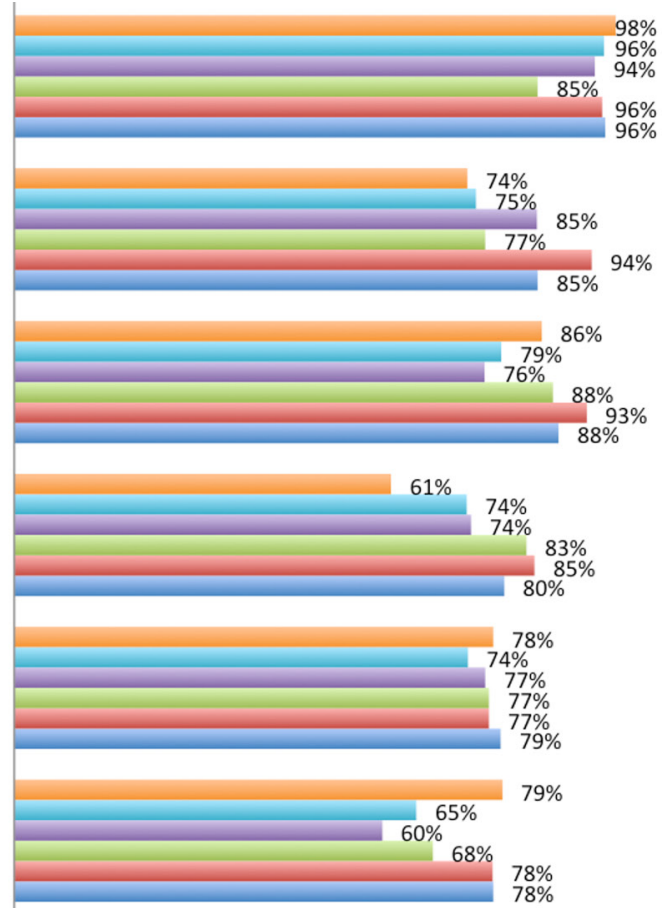

西
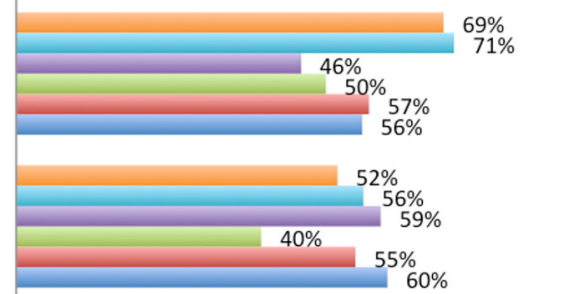

\section{(1)}

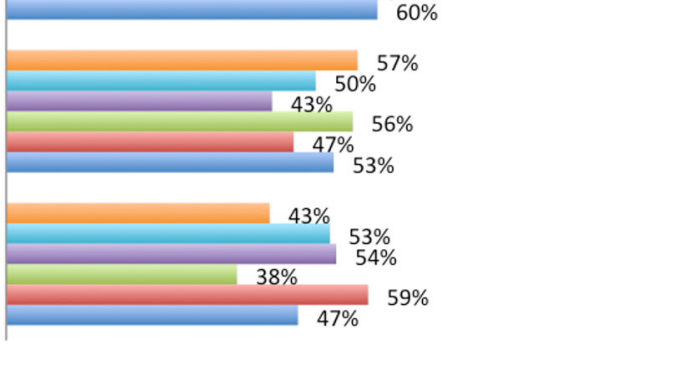

Family Medicine Physician $(n=50)$ Surgeon $(n=50)$

Family Medicine PA ( $\mathrm{n}=52) \quad$ Surgical PA $(\mathrm{n}=16)$

Family Medicine NP $(n=54) \quad$ Surgical NP $(n=50)$

Figure 3 Top box scores: Favourable attitudes towards SDM by clinician type, adjusted for participant characteristics. NP, nurse practitioner; PA, physician assistant; SDM, shared decision-making.

a majority of clinicians $(71.7 \% ; 95 \%$ CI 65.9 to 77.0$)$ did not think that SDM could increase their legal risk. Physicians in both surgical $(70.5 \% ; 95 \%$ CI 57.0 to 84.0 ; $\mathrm{p}=0.025)$ and family medicine $(69.3 \%$; $95 \%$ CI 55.9 to 82.7; $\mathrm{p}=0.031)$ specialties were significantly more likely than family medicine PAs $(47.0 \%$; $95 \%$ CI 33.3 to 60.8$)$ to be comfortable if a shared decision deviated from their preferred course of action. See figure 3 for full results of SDM attitudinal items, adjusted for observed clinician characteristics. Full logistic regression results are available in online supplementary materials.

\section{Preferred approach to decision-making}

Preferred approaches to decision-making, as measured through multiple-choice responses to a clinical scenario, were consistent across professions and clinical specialties. A majority of all participants (53\%; 95\% CI 46.8 to 59.0 ) indicated that in the given clinical scenario, they would take an informative approach to decision-making, using 'evidence-based information to help the patient understand his health condition and all possible treatment options so he can decide on a treatment plan based on his values'. A substantial proportion (37\%; 95\% CI 31.4 
to 43.2) preferred a deliberative approach aligned with SDM, where they 'discuss the patient's health-related values with him and deliberate together using evidencebased information to decide on his treatment plan'. Another $7 \%$ (95\% CI 4.0 to 10.3 ) hypothetically chose an interpretive approach, in which they would 'help the patient understand his personal values and suggest evidence-based treatment options that fit those values'. Only 3\% (95\% CI 1.5 to 6.2) favoured a paternalistic approach in which they would 'determine the patient's clinical situation independent of his values and present him with evidence supporting [their] decision'.

\section{DISCUSSION}

\section{Key findings}

This survey was the first to compare knowledge and attitudes about SDM across diverse US-based clinician groups. We found knowledge to be limited across professions and clinical specialties. Knowledge about risk communication and the impact of SDM on health and treatment adherence outcomes was lowest. Performance on some individual knowledge items varied by clinician type, with family medicine PAs performing best on several knowledge items and surgeons sometimes least knowledgeable. However, this study did not identify clear overall knowledge differences between NPs, PAs and physicians across family medicine and surgical specialties. Further, very few participants were able to provide a complete definition of SDM that included reference to patient and clinician participation and to the evidence on which shared decisions should be based.

Despite limited knowledge, confidence in performing SDM was high, particularly among family medicine NPs. Additionally, three-quarters of participants felt that engaging in SDM does not take too much time, which demonstrated a positive attitude towards SDM. Physicians in both specialties were more likely than family medicine PAs to feel that it is okay for a shared decision to stray from their preferred course of action. While half of all participants favoured an informative approach to decision-making, a substantial proportion said they would engage in a deliberative approach aligned with SDM when faced with a hypothetical clinical scenario.

\section{Context in existing literature}

The confidence we observe with regard to clinicians' self-assessment of their ability to engage in SDM paired with limited knowledge and difficulty defining SDM is consistent with previous work suggesting a lack of consistency in use of the term SDM in scholarly and clinical communities. ${ }^{18} 33$ The limited knowledge we observed with regard to risk communication also corroborates prior research on SDM knowledge among medical students and health professional trainees. ${ }^{34}$ Further, surgeons performed more poorly than other professions or specialties on several knowledge items, which is consistent with prior research establishing low levels of support for SDM among surgeons. ${ }^{14} 19$

More broadly, Kruger and Dunning ${ }^{35}$ previously demonstrated that limited knowledge of a particular domain prevents individuals from being aware of their own lack of competence in that same domain. ${ }^{35}$ Our findings of high confidence in performing SDM paired with limited knowledge of SDM may demonstrate this Dunning-Kruger effect. As a quarter of participants in the current study reported previous formal SDM training, that prior exposure to SDM training may have enhanced these individuals' confidence in engaging in SDM despite low to moderate knowledge retention.

Additionally, the preference expressed by many participants for an informative approach to decision-making over a more deliberative SDM approach may reflect prior work on this topic, ${ }^{28}$ namely, a misconception that SDM leaves patients to make decisions on their own. ${ }^{18}$ Medical ethics have long held non-abandonment as a central obligation for physicians. ${ }^{36}$ The current study suggests a tendency for clinicians to interpret SDM as a process of informing patients and subsequently allowing them complete autonomy to make clinical decisions, which might be interpreted by a patient as abandonment. However, the guiding ethical principles of SDM recognise autonomy in the context of relationships and mutual dependencies that allow and encourage clinicians and patients to make decisions together. ${ }^{7}$ Additionally, despite an expressed preference in this sample for information provision over a full SDM process, it is noteworthy that very few participants preferred a paternalistic approach to clinical decision-making in which the values and preferences of the patient are not considered. Further, as respondents were asked about their preferred physician-patient relationship model at the end of the survey after respondents were primed with two batteries of SDM-related items, it is possible that this item reflects knowledge of SDM as much, if not more, than it demonstrates respondents' preferred approaches to clinical decision-making.

While a compelling accumulation of existing literature cites time constraints as a prominent barrier to $\mathrm{SDM},{ }^{17} 18203738$ we find in this sample general disagreement with the idea that SDM takes too much time. More research among diverse and representative samples is needed to validate these findings and to further examine and delineate the contexts in which SDM is viewed as a burden due to time constraints versus those in which time is not believed to be a barrier. Further, our finding that most physicians feel it is okay for a shared decision to stray from what they feel is the most clinically appropriate course of action lies in contrast to prior literature finding that physicians tend to support SDM in situations where they do not feel strongly about one treatment alternative. ${ }^{199}$ In the context of prior research, our results suggest that attitudes towards SDM may be evolving, with clinicians increasingly open to this style of practice. However, knowledge is low and training should become mainstream. 


\section{Strengths and limitations}

To our knowledge, this study represents the first US national survey comparing SDM knowledge and attitudes across diverse clinician groups including NPs, PAs and physicians. The survey instrument was rigorously developed based on a literature search of high-quality evidence, primarily including systematic reviews, and was based on a previously tested survey. We used a healthcare market research company to implement the survey for ease of recruitment, survey administration and disbursement of honoraria. Use of a healthcare market research company for survey administration and disbursement of honoraria allowed the research team no access to respondents' personally identifiable information, which may have favourable implications in limiting social desirability bias.

However, our sample was derived from an online panel of respondents and may not be representative of the full US populations of these professionals, allowing for possible selection bias. Further, we were unable to fully field the surgical PA quota in this exploratory study. Therefore, due to the small sample size, estimates of knowledge and attitudes of surgical PAs are at particular risk of bias. Multiple testing may have, in some cases, caused us to find statistical significance by chance. Additionally, it is possible to interpret the item wording 'Shared decision-making can only be done with patients who are sufficiently educated to discuss treatment or screening options' in multiple ways. It is not clear whether it references formal educational attainment or education provided by the clinician about a health condition and possible treatment options. Therefore, responses to this attitude item must be interpreted with caution. Similarly, there are some individual SDM studies that demonstrate an increase in adherence and other health-related outcomes as a result of clinicians' SDM-promoting behaviours. ${ }^{40}$ While the knowledge items related to the impact of SDM on health behaviours and outcomes within this survey were specific to the role of patient-facing SDM interventions and were based on evidence synthesis within a high-quality Cochrane systematic review, ${ }^{23}$ it is possible that the existence of related studies with contradictory findings may have inflated the proportion of incorrect answers on the knowledge items relating to the impact of SDM interventions on health behaviours and outcomes. Additionally, the true-false design of the knowledge items without a 'don't know' option limits our ability to differentiate incorrectly answered items as reflective of a lack of knowledge versus an incomplete understanding of the currently available research evidence.

\section{CONCLUSION}

The positive attitudes towards SDM expressed in this select sample suggest the possibility that acceptance of SDM may be an emerging norm within the healthcare field. While we see few participants across professions and clinical specialties express negative views about SDM, we also observe high confidence in the face of limited understanding — which may negate the advantage conferred by positive attitudes. As we found knowledge of SDM to be limited despite positive attitudes towards SDM, it may be appropriate to prioritise SDM training among these professional groups in order to encourage all professions to take up SDM, rather than leaving SDM to physicians as has been done in the past.

Contributors RCF contributed to the design of the work, analysis and interpretation of data and drafting the work. RWY, MA, PJB and GE contributed to the design and revision of the work. DS contributed to data analysis and revision of the work. M-AD contributed to the conception and design of the work, interpretation of data and revision of the work.

Funding The authors have not declared a specific grant for this research from any funding agency in the public, commercial or not-for-profit sectors.

Competing interests $M-A D$ was involved in developing the Option Grid patient decision aids, which are licensed to EBSCO Health. She receives consulting income from EBSCO Health and may receive royalties in the future. $M-A D$ is also a consultant for ACCESS Community Health Network and delivers shared decision making training to ACCESS clinicians. GE has edited and published books that provide royalties on sales by the publishers: the books include Shared Decision Making (Oxford University Press) and Groups (Radcliffe Press). He has in the past provided consultancy for (1) Emmi Solutions LLC who develop patient decision support tools; (2) National Quality Forum on the certification of decision support tools; (3) Washington State Health Department on the certification of decision support tools; (4) SciMentum LLC, Amsterdam (workshops for shared decision making). GE is Director of \&think LLC which owns the registered trademark for Option GridsTM patient decision aids. He provides consultancy in the domain of shared decision making and patient decision aids to: (1) Access Community Health Network, Chicago (Federally Qualified Medical Centers) and to (2) EBSCO Health Option GridsTM patient decision aids. GE initiated the Option Grid Collaborative, tools that are hosted on a website managed by Dartmouth College, on http:// optiongrid.org/). Existing Option Grids hosted at this website are freely available until such time as the tools have expired. He owns copyright in measures of shared decision making and care integration, namely CollaboRATE, IntegRATE and Observer OPTION. These measures are freely available for use.

Patient consent Not required.

Ethics approval Dartmouth College's Committee for the Protection of Human Subjects (study \#30303).

Provenance and peer review Not commissioned; externally peer reviewed.

Data sharing statement A deidentified participant-level dataset is available on request to the corresponding author (Marie-Anne Durand).

Open access This is an open access article distributed in accordance with the Creative Commons Attribution Non Commercial (CC BY-NC 4.0) license, which permits others to distribute, remix, adapt, build upon this work non-commercially, and license their derivative works on different terms, provided the original work is properly cited, appropriate credit is given, any changes made indicated, and the use is non-commercial. See: http://creativecommons.org/licenses/by-nc/4.0/.

\section{REFERENCES}

1. Schottenfeld L, Petersen D, Peikes D, et al. Creating patient-centered team-based primary care. 2016.

2. Goldberg DG, Beeson T, Kuzel AJ, et al. Team-based care: a critical element of primary care practice transformation. Popul Health Manag 2013;16:150-6.

3. Brush JE, Handberg EM, Biga C, et al. 2015 ACC Health policy statement on cardiovascular team-based care and the role of advanced practice providers. J Am Coll Cardiol 2015;65:2118-36.

4. Swan M, Ferguson S, Chang A, et al. Quality of primary care by advanced practice nurses: a systematic review. Int J Qual Health Care 2015;27:396-404.

5. Hojat M, Fields SK, Gonnella JS. Empathy: an NP/MD comparison. Nurse Pract 2003;28:45-7.

6. Laurant M, Harmsen M, Wollersheim $\mathrm{H}$, et al. The impact of nonphysician clinicians. Medical Care Research and Review 2009;66:36S-89. 
7. Elwyn G, Frosch D, Thomson R, et al. Shared decision making: a model for clinical practice. J Gen Intern Med 2012;27:1361-7.

8. Barry MJ, Edgman-Levitan S. Shared decision making--pinnacle of patient-centered care. N Engl J Med 2012;366:780-1.

9. Charles C, Gafni A, Whelan T. Shared decision-making in the medical encounter: what does it mean? (or it takes at least two to tango). Soc Sci Med 1997;44:681-92.

10. Cooper RA, Henderson T, Dietrich CL. Roles of nonphysician clinicians as autonomous providers of patient care. JAMA 1998;280:795

11. Légaré F, Stacey D, Pouliot $\mathrm{S}$, et al. Interprofessionalism and shared decision-making in primary care: a stepwise approach towards a new model. J Interprof Care 2011;25:18-25.

12. Clark NM, Nelson BW, Valerio MA, et al. Consideration of shared decision making in nursing: a review of clinicians' perceptions and interventions. Open Nurs J 2009;3:65-75.

13. Légaré F, Stacey D, Gagnon S, et al. Validating a conceptual model for an inter-professional approach to shared decision making: a mixed methods study. J Eval Clin Pract 2011;17:554-64.

14. Chan CM, Ahmad WA. Differences in physician attitudes towards patient-centredness: across four medical specialties. Int J Clin Pract 2012;66:16-20.

15. Eysenbach G. Improving the quality of Web surveys: the Checklist for Reporting Results of Internet E-Surveys (CHERRIES). J Med Internet Res 2004;6:e34.

16. Durand MA, Yen R, Barr PJ, et al. Assessing medical student knowledge and attitudes about shared decision making across the curriculum: protocol for an international online survey and stakeholder analysis. BMJ Open 2017;7:e015945.

17. Légaré F, Witteman HO. Shared decision making: examining key elements and barriers to adoption into routine clinical practice. Health Aff 2013;32:276-84.

18. Légaré $\mathrm{F}$, Ratté $\mathrm{S}$, Gravel $\mathrm{K}$, et al. Barriers and facilitators to implementing shared decision-making in clinical practice: update of a systematic review of health professionals' perceptions. Patient Educ Couns 2008;73:526-35

19. Pollard S, Bansback N, Bryan S. Physician attitudes toward shared decision making: a systematic review. Patient Educ Couns 2015;98:1046-57.

20. Schoenfeld EM, Goff SL, Elia TR, et al. The Physician-asStakeholder: an exploratory qualitative analysis of physicians motivations for using shared decision making in the emergency department. Acad Emerg Med 2016;23:1417-27.

21. Elston Lafata J, Brown RF, Pignone MP, et al. Primary care physicians' support of shared decision making for different cancer screening decisions. Med Decis Making 2017;37:70-8.

22. Probst MA, Kanzaria HK, Frosch DL, et al. Perceived appropriateness of shared decision-making in the emergency department: a survey study. Acad Emerg Med 2016;23:375-81.

23. Stacey $D$, Légaré $F$, Lewis $K$, et al. Decision aids for people facing health treatment or screening decisions. Cochrane Database Syst Rev 2017;4:CD001431.
24. Akl EA, Oxman AD, Herrin J, et al. Using alternative statistical formats for presenting risks and risk reductions. Cochrane Database Syst Rev 2011:CD006776 (Published Online First: 16 Mar 2011).

25. Nassar N, Roberts CL, Raynes-Greenow CH, et al. Evaluation of a decision aid for women with breech presentation at term: a randomised controlled trial [ISRCTN14570598]. BJOG 2007;114:325-33.

26. Watson E, Hewitson P, Brett J, et al. Informed decision making and prostate specific antigen (PSA) testing for prostate cancer: a randomised controlled trial exploring the impact of a brief patient decision aid on men's knowledge, attitudes and intention to be tested. Patient Educ Couns 2006;63:367-79.

27. Shay LA, Lafata JE. Where is the evidence? A systematic review of shared decision making and patient outcomes. Med Decis Making 2015;35:114-31.

28. Emanuel EJ, Emanuel LL. Four models of the physician-patient relationship. JAMA 1992;267:2221-6.

29. Fields SK, Hojat M, Gonnella JS, et al. Comparisons of nurses and physicians on an operational measure of empathy. Eval Health Prof 2004;27:80-94.

30. Wilson Van Voorhis CR, Morgan BL. Understanding power and rules of thumb for determining sample sizes. Tutor Quant Methods Psychol 2007:3:43-50.

31. Peduzzi P, Concato J, Kemper E, et al. A simulation study of the number of events per variable in logistic regression analysis. $J$ Clin Epidemiol 1996;49:1373-9.

32. Vittinghoff E, McCulloch CE. Relaxing the rule of ten events per variable in logistic and cox regression. Am J Epidemiol 2007:165:710-8.

33. Moumjid N, Gafni A, Brémond A, et al. Shared decision making in the medical encounter: are we all talking about the same thing? Med Decis Making 2007;27:539-46.

34. Yen RW, Durand M-A, Barr PJ, et al. Evaluating medical students knowledge of and attitudes towards shared decision-making: a multinational cross-sectional study. Lyon: International Shared Decision Making Conference, 2017.

35. Kruger J, Dunning D. Unskilled and unaware of it: how difficulties in recognizing one's own incompetence lead to inflated selfassessments. J Pers Soc Psychol 1999;77:1121-34.

36. Quill TE, Cassel CK. Nonabandonment: a central obligation for physicians. Ann Intern Med 1995;122:368.

37. Kanzaria HK, Brook RH, Probst MA, et al. Emergency physician perceptions of shared decision-making. Acad Emerg Med 2015;22:399-405.

38. Légaré $F$, Thompson-Leduc P. Twelve myths about shared decision making. Patient Educ Couns 2014;96:281-6.

39. Watson DB, Thomson RG, Murtagh MJ. Professional centred shared decision making: patient decision aids in practice in primary care. BMC Health Serv Res 2008;8:5.

40. Wilson SR, Strub P, Buist AS, et al. Shared treatment decision making improves adherence and outcomes in poorly controlled asthma. Am J Respir Crit Care Med 2010;181:566-77. 